\title{
The effect of heat treatment on the compressive strength of cement-slag mortars
}

\author{
Hashim Abdul Razak, Fathollah Sajedi
}

Temperature variation caused by the heat of hydration in mass

concrete or the change of external environment, has a considerable

influence on the mechanical properties of early-age concrete.

Mechanical properties such as compressive strength are factors

to be considered in the design and construction of concrete structures.

Therefore, the effects of temperature and aging on the

mechanical properties should be studied and quantified. According

to the experimental results, concrete subjected to high temperatures

at early ages attains higher early-age compressive and splitting

tensile strengths but has lower later-age compressive and

splitting tensile strengths than concrete subjected to normal

temperatures [1]. Mortar and concrete are the most important

elements of structures and, if well-designed, can be durable construction

materials. One effective way to reduce the environmental

impact is to use mineral admixtures as a partial cement replacement.

This strategy has the potential to reduce costs, conserve

energy, and reduce the volume of waste. Mineral admixtures are

silica-based materials such as ground granulated blast furnace slag

(GGBFS), fly ash, and silica fume. Mineral admixtures are being used more and more for concrete because of their strength and

durability [2]. The presence of some mineral admixtures such as

GGBFS in the cement, can modify the kinetics of hydration, reduce

the heat evolution, and produce additional calcium silicate

hydrates $(\mathrm{C}-\mathrm{S}-\mathrm{H}) \mathrm{gel}$. These admixtures result in a noticeable performance increase in the concrete in hot climates as the negative

effect of the temperature is partly reduced by the pozzolanic reaction,

their weak hydration heat, and their great activation energy.

The use of pozzolans as supplementary cementing materials has been found to provide noticeable enhancement to the mechanical properties of concrete and mitigate the damage, which is of particular concern for durability. Based on various studies on the effects of heat curing on cementitious systems, heat treatment of concrete has become a regulated practice in the precast concrete industry. In the 1980s Germany introduced heat curing regulatory particles specifying the parameters of the curing cycle including a maximum temperature of 60 _C. Presently, certain countries including Canada, the United States, South Africa, and most European countries have developed similar specifications for the regulation of 
heat curing for precast concrete. The maximum curing temperature imposed is often 60-70_C. The length of heat exposure is not usually included in these specifications as this can be adjusted without adversely affecting performance [3]. Several researchers $[1,2,4-6]$ reported that a high temperature improves strength at early ages. At a later age, the important numbers of formed hydrates have no time to arrange suitably and this causes a loss of ultimate strength; this behaviour has been called the crossover effect $[7,8]$. For ordinary Portland cement (OPC), it appears that the ultimate strength decreases with curing temperature nearly linearly [9]. Since GGBFS itself is nothing more than a latent hydraulic binder, it must be activated to react and provide the desirable mechanical properties. One of these activation methods is the thermal method [10]. The objective of this study is to produce a data inventory of the early-age behaviour of some mechanical properties, such as the compressive strength of mortars with temperature, as well as to investigate the relationship between compressive strength with temperature and the relationship between the compressive strength of specimens cured in air under room temperature and water at 3 and 7 days, for $40 \%$ and $50 \%$ levels of replacement slag.

Experimental procedure

Mix proportions and curing

Table 1 represents the mix proportions for different mortars. In all the mixes $w / b=0.33, s / b=2.25$. Silica sand was used in the mixes. At first, based on grain size distribution, five grades of silica sand were mixed. Two minutes after that cement and replacement slag were put into the mixture, followed by four minutes of mixing.

Notes: OM = OPC mortar, OSM/i = OPC_slag mortar for $\mathrm{i} \%$ replacement with slag.

Mixing water was then added to the mix, and mixing was continued for two minutes, after which the required amount of super plasticizer was added. Mixing was continued for two minutes; finally, the moulds were filled with fresh mortar in two layers. Each layer was compacted with ten impacts by a rod of $16 \mathrm{~mm}$ diameter. The specimens were demoulded $24 \mathrm{~h}$ after casting and heated in water at $60 \_C$ for the required time as mentioned in Table 1, and then cured in air under room temperature $28 \pm 4$ _C with $70 \pm 10 \%$ relative humidity and water with $23 \pm 3 \_C$ until the test day.

Properties of materials

Cement 
The cement used in all the mixes was OPC. ASTM C109-99 [11]

was used for the determination of the compressive strength of hydraulic cement mortars using $50 \mathrm{~mm}$ specimen cubes. The specific gravity of the cement used was about 3.14. Based on particle size analysis tests, the specific surface area (SSA) for OPC particles was determined to be $1.8939 \mathrm{~m} / \mathrm{g}$. The chemical composition of the OPC used in this study was determined by the X-ray fluorescence spectrometry (XRF) test, as given in Table 2.

Slag

The specific gravity of slag was approximately 2.87 , with its bulk density varying between 1180 and $1250 \mathrm{~kg} / \mathrm{m} 3$. The colour of GGBFS is normally whitish (off-white). Based on the results of the particle size analysis test, the SSA for GGBFS was determined to be $3.5972 \mathrm{~m} / \mathrm{g}$. It can be seen that SSA slag is 1.9 times of SSA OPC, which means that the particles of slag are $90 \%$ finer than those of OPC. The composition of slag is given in Table 2. As with all cementing materials, the reactivity of the slag is determined by its SSA. In general, increased fineness results in better strength development, however, in practice; fineness is limited by economics, performance considerations and factors such as setting time and shrinkage [12]. For better performance, the fineness of GGBFS must be greater than that of OPC. Based on the definition of the slag activity index (SAI) in ASTM C989 [13], it can be seen that $S A I=(S P / P) \_100$; where $S P=$ average compressive strength of slag-reference cement mortar cubes and $\mathrm{P}=$ average compressive strength of reference cement mortar cubes. Based on this definition, the slag used in the tests is classified into Grade 120. A sample calculation is shown in the bottom of Table 2 [14].

Aggregates

The fine aggregate used in the mixes is graded silica sand with specific gravity, fineness modulus, and water absorption $2.68 \%$, $3.88 \%$, and $0.93 \%$, respectively. The maximum aggregate size is $4.75 \mathrm{~mm}$. The grain size distribution of the fine aggregate is given in Table 3 and the grain size distribution diagram is shown in Fig. 1 [15].

Super plasticizer

In order to have a proper consistency with a low $\mathrm{w} / \mathrm{b}$ ratio, super plasticizer is required. The specific gravity of super plasticizer is approximately 1.195 , is dark brown in colour, with a $\mathrm{pH}$ in the range of $6-9$. The consumed amount of super plasticizer in the mortar depends on the replacement level of slag. It is a chloride-

free product that meets ASTM C494 [16]. The basic components

are synthetic polymers, which allow the mixing water to 
be reduced considerably. The dosage of super plasticizer generally

varies from 0.8 to 1.2 litre/ $(100 \mathrm{~kg})$ of cement. Other dosages may

be recommended in special cases according to specific job conditions.

It is compatible with all cements and admixtures meeting

ASTM and UNI standards.

Water

The water used in all the mixes and curing of the specimens was

potable water.

Test and mixing procedures

Test for fresh mortar

In order to have appropriate consistency for each mortar, after

casting, a flow table test ASTM C230/C230M-08 [17] was

performed. The range of flow amounts were 220-235 mm. First,

some mortar was put in the truncated brass cone in two layers

and each layer was compacted 10 times by a steel rod of $16 \mathrm{~mm}$

diameter. The cone was then lifted and the mortar was collapsed

on the flow table. Following that, both the table and mortar were

jolted 15 times in a period of $60 \mathrm{~s}$. The jolting of the table, allowed

the mortar to spread out and the maximum spread to the two

edges of the table was recorded. The average of both records was

calculated as flow in $\mathrm{mm}$.

Full text available at :

http://www.sciencedirect.com/science/article/pii/S0261306911003074

http://ac.els-cdn.com/S0261306911003074/1-s2.0-S0261306911003074-main.pdf?_tid=cf7886fa-781f-11e3-

aff7-00000aacb362\&acdnat $=1389156557$ dee611520f2b3bdf24a0177163ea4af3 